\title{
Brief Engagement and Acceptance Coaching for Hospice Settings (the BEACHeS study): results from a Phase I study of acceptability and initial effectiveness in people with non-curative cancer
}

Nicholas J. Hulbert-Williams 1*, Sabrina F. Norwood', David Gillanders², Anne M. Finucane ${ }^{2,3}$, Juliet Spiller ${ }^{3}$, Jenny Strachan ${ }^{3}$, Susan Millington ${ }^{4}$, Joseph $\mathrm{Kreft}^{1}$ and Brooke Swash ${ }^{1}$

\begin{abstract}
Objectives: Transitioning into palliative care is psychologically demanding for people with advanced cancer, and there is a need for acceptable and effective interventions to support this. We aimed to develop and pilot test a brief Acceptance and Commitment Therapy (ACT) based intervention to improve quality of life and distress.

Methods: Our mixed-method design included: (i) quantitative effectiveness testing using Single Case Experimental Design (SCED), (ii) qualitative interviews with participants, and (iii) focus groups with hospice staff. The five-session, in-person intervention was delivered to 10 participants; five completed at least $80 \%$.

Results: At baseline, participants reported poor quality of life but low distress. Most experienced substantial physical health deterioration during the study. SCED analysis methods did not show conclusively significant effects, but there was some indication that outcome improvement followed changes in expected intervention processes variables. Quantitative and qualitative data together demonstrates acceptability, perceived effectiveness and safety of the intervention. Qualitative interviews and focus groups were also used to gain feedback on intervention content and to make design recommendations to maximise success of later feasibility trials.
\end{abstract}

Conclusions: This study adds to the growing evidence base for ACT in people with advanced cancer. A number of potential intervention mechanisms, for example a distress-buffering hypothesis, are raised by our data and these should be addressed in future research using randomised controlled trial designs. Our methodological recommendations - including recruiting non-cancer diagnoses, and earlier in the treatment trajectory-likely apply more broadly to the delivery of psychological intervention in the palliative care setting.

This study was pre-registered on the Open Science Framework (Ref: 46,033) and retrospectively registered on the ISRCTN registry (Ref: ISRCTN12084782).

Keywords: Acceptance and commitment therapy, Coaching, Quality of life, Distress, Palliative, Cancer, Hospice

*Correspondence: n.hulbertwilliams@chester.ac.uk

${ }^{1}$ Centre for Contextual Behavioural Science, School of Psychology,

University of Chester, Chester, UK

Full list of author information is available at the end of the article

\section{Introduction}

Cancer is the second most common cause of death globally, responsible for 9.6 million deaths in 2018 [1]. By 2030 , an estimated 4 million people will be living with or

(c) The Author(s) 2021. Open Access This article is licensed under a Creative Commons Attribution 4.0 International License, which permits use, sharing, adaptation, distribution and reproduction in any medium or format, as long as you give appropriate credit to the original author(s) and the source, provide a link to the Creative Commons licence, and indicate if changes were made. The images or other third party material in this article are included in the article's Creative Commons licence, unless indicated otherwise in a credit line to the material. If material is not included in the article's Creative Commons licence and your intended use is not permitted by statutory regulation or exceeds the permitted use, you will need to obtain permission directly from the copyright holder. To view a copy of this licence, visit http://creativecommons.org/licenses/by/4.0/. The Creative Commons Public Domain Dedication waiver (http://creativeco mmons.org/publicdomain/zero/1.0/) applies to the data made available in this article, unless otherwise stated in a credit line to the data. 
beyond cancer in the UK [2], and the number of people requiring palliative care is expected to rise substantially [3].

Palliative care aims to maintain quality of life and ease physical and psychological symptom burden. NICE quality standards for adults approaching end of life includes holistic care, encompassing psychological, emotional, and social support [4]. Despite this, people with advanced cancer experience significant psychological and social distress $[5,6]$. Transition points, such as that into palliative care, can be particularly psychologically demanding as patients adjust to altered life expectations $[7,8]$. This can impact their ability to plan for the future and willingness to engage in advance care planning.

Acceptance and Commitment Therapy (ACT) is a psychological intervention that may support cancer patients approaching end of life. ACT aims not to change or reduce distressing thoughts, but to coach ways of limiting the influence of those thoughts and feelings on day-today living and goal achievement by increasing psychological flexibility [9]. ACT acknowledges that distress and suffering are normal, rational reactions to challenging life events. Techniques such as mindfulness, acceptance, and values identification help people to direct their behaviours towards living in the present moment rather than focusing on fears or anxieties. ACT can support people to cope with feelings of grief and demoralisation which may improve quality of life and sense of meaning [10].

$\mathrm{ACT}$ has a growing evidence-base in cancer [11], with acceptability indicated in those with advanced disease [12]. In one trial comparing ACT and cognitive behavioural therapy in patients with advanced ovarian cancer, ACT was associated with improved quality of life and reduced distress [13]. In more recent pilot studies, ACT was (non-significantly) associated with decreased symptom interference [14], and significantly improved sleep, distress and hyperarousal [15]. UK-based research reports that it is feasible to deliver ACT to people with advanced cancer, but concluded that more work is needed to robustly test efficacy [16].

Our objectives were to develop and test acceptability and potential efficacy of a brief ACT-based coaching intervention to support people with an incurable cancer diagnosis, at the point of referral to a hospice service. As a secondary aim, our study modelled psychological mechanisms (i.e. psychological flexibility) as a vital first step in fully evaluating ACT as a complex intervention for palliative care.

\section{Method}

The design, including intervention development, has been reported previously [17]. All study protocols received ethical and research governance approvals from the UK Health Research Authority (Ref: 18/WA/0087). The study was pre-registered on the Open Science Framework (Ref: 46,033; Date Registered 12/06/2018) and retrospectively registered on the ISRCTN registry (Ref: ISRCTN12084782; Date Registered 31/01/2021). Study methods were carried out in accordance with principles for medical research involving human subjects as laid down in the World Medical Association Declaration of Helsinki.

\section{Design}

A mixed-methods design was used, as is recommended for trial development [18]. Patient and stakeholder engagement featured heavily to maximise acceptability and implementation [19]. To assess initial effectiveness, we used a single-case experimental design (SCED) [20], allowing for highly controlled delivery alongside patientcentred, in-depth, analysis [21]. SCEDs are experimental designs where the efficacy of an intervention can be closely examined, with each participant providing their own 'control' data by completing comprehensive measurement prior to, during, and after implementation of the intervention. Frequent, repeated measurement of process and outcome lend themselves to a mode of within-participant analysis that can be conducted on a very small number of participants. SCEDs are common in psychological intervention research and have established utility in cancer research [22, 23]. Though not designed as a feasibility trial, the design permitted piloting recruitment, intervention and data collection methods.

\section{Participants}

Anyone over 16 years of age at the point of referral into specialist hospice care at recruitment sites (one in England; two in Scotland) following an incurable cancer diagnosis was eligible. Recruitment took place between May 2018 and March 2019. Study invitation took place during the participant's initial appointment with the hospice specialist nurse.

High attrition was expected given prognosis [24]; accordingly, we excluded those with less than four months life expectancy to maximise trial completion likelihood. We aimed to recruit 20 people, expecting a $50 \%$ intervention completion rate. Given that SCED is an idiographic, within-participants approach, this is sufficient for our study aims $[25,26]$.

\section{Intervention}

The Brief Engagement and Acceptance Coaching for Hospice Settings (BEACHeS) Intervention contained five in-person, one-to-one sessions, each lasting 40-60 min (Table 1). Following an initial assessment, ACT content was delivered over three subsequent sessions, 
Table 1 Outline of intervention content

\begin{tabular}{|c|c|c|}
\hline Session & Purpose & Content \\
\hline 1 & $\begin{array}{l}\text { Module A: Assessment } \\
\text { \& Engagement }\end{array}$ & $\begin{array}{l}\text { Warmth, empathy, positive regard. History taking, typical responses to transition, beginning baseline monitoring } \\
\text { and introducing measurement protocol and concepts }\end{array}$ \\
\hline \multirow[t]{4}{*}{$2-4$} & Module B: Workability ${ }^{a}$ & $\begin{array}{l}\text { Review of typical responses to distress/suffering and greater contact with the consequences, linking ineffective } \\
\text { strategies with control, avoidance and cognitive fusion }\end{array}$ \\
\hline & Module C: Awareness & $\begin{array}{l}\text { Teaching awareness skills, linking to greater behavioural choice, mindfulness exercises, } 5 \text { senses experience, mindful } \\
\text { eating a raisin, 10-min mindfulness audio exercise given for homework }\end{array}$ \\
\hline & Module D: Openness & $\begin{array}{l}\text { Demonstrating the greater effectiveness of willingness to have difficult thoughts and feelings and at the same time, } \\
\text { stepping back from such inner experiences }\end{array}$ \\
\hline & Module E: Engagement & $\begin{array}{l}\text { Linking behavioural effectiveness with desired outcomes and qualities of actions, in order to live with purpose and } \\
\text { meaning }\end{array}$ \\
\hline 5 & Module F: Follow-up & $\begin{array}{l}\text { Review of progress, barriers to practice, anticipation of future challenges and how ACT skills could be used, behav- } \\
\text { ioural rehearsal of effective responses, commitments to next steps. Ending contact }\end{array}$ \\
\hline
\end{tabular}

${ }^{a}$ The workability module was delivered to all participants at the start of session 2, however, the modular format allowed for awareness, openness and engagement to be delivered in whichever order was most appropriate for each participant [19]

approximately one week apart. The fifth session, one month later, consolidated and maintained gains, and problem-solved difficulties. In-person work was supplemented with home-practice and exercises. Written session summaries were provided to support change and encourage sharing of content with significant others.

In developing the manual we selected exercises and metaphors that were suitable for participants with a noncurative cancer diagnosis. For example, we avoided those exercise and metaphors common to other ACT intervention manuals that involve the participant considering their future life choices, instead developing tailored metaphors more appropriate to those who may be close to the end of life (see our published protocol for more detail) [17]. The manual was peer-reviewed by five independent $\mathrm{ACT}$ or palliative care experts.

The intervention was designed to be delivered by appropriately trained Clinical Psychologists or BABCP accredited psychological therapists to enable optimal experimental control, and to establish manual safety prior to delivery by other healthcare professionals in future trials. Two intervention facilitators were appointed and their competency independently assessed against published criteria [27] using video-simulation. Supervision was provided by a Clinical Psychologist and delivery audio-recorded for fidelity checking.

By developing an intervention that is both brief and manualised, we aimed to optimise long term cost-effectiveness and implementation possibilities.

\section{Procedure and outcome assessments}

Eligibility screening was undertaken by hospice-based community specialist nurses who provided study information and gained verbal consent to refer patients to the research team. A researcher then contacted participants by telephone to arrange the initial assessment session, where informed consent was taken and baseline measures assessed. These measures were repeated prior to each subsequent intervention session:

\section{Primary outcome: quality of life}

Administration of the Functional Assessment of Chronic Illness Therapy (Palliative Care) [28] provided primary outcome data. This scale comprises five quality of life domains-physical (7 items), social/family (7 items), emotional (6 items), functional (7 items) and additional concerns (19 items) - each scored on a scale of 0 (anchored to poorer quality of life) to 4 (anchored to better quality of life). Participants answer based on their experiences over the previous seven days.

\section{Secondary outcomes: distress}

Distress was assessed using the single-item Distress Thermometer [29], a commonly used screening tool in cancer settings (score range 0 to 10; higher ratings represent worse distress). Participants indicate their distress level over the previous seven days.

Postulated Intervention mechanism: psychological flexibility Psychological flexibility was assessed using the 23-item Comprehensive Assessment of Acceptance \& Commitment Therapy (CompACT) [30]; separate component scores-openness to experience, behavioural awareness and valued action-map closely to the three core intervention sessions making this ideal for our study. Subscale scores range from 0 to 42 , with higher scores representing greater psychological flexibility.

\section{Daily assessments}

Daily recordings of key process and outcome measures are integral to SCED studies and were assessed using either a smart-phone based app (PACO: Personal 
Analytics Companion) or paper-and-pen alternative. Participants completed the Brief Acceptance Measure (BAM) [31], a three-item measure of psychological flexibility (score range 0-30 where high scores indicate greater flexibility), and a single quality of life question where participants indicated their current overall health from 0 (worst imaginable) to 100 (best imaginable). All daily assessments ask participants to provide a rating based on how they were feeling on that particular day.

\section{Qualitative data}

Participants who completed the intervention, or actively withdrew, were invited to a qualitative interview. A choice of telephone or in-person interview (at the hospice) was offered. The interview schedule aimed to elucidate experiences of study participation, acceptability and perceived intervention effectiveness. Debrief information was provided on study completion.

After closing recruitment, staff involved at each sites were invited to a focus group discussion about challenges and barriers to recruiting participants and supporting the study in the hospice setting. We also sought opinions about different study designs for follow-on research. Interviews and focus groups were audio-recorded and transcribed verbatim for analysis.

\section{Analysis}

In this paper we focus on participants meeting intervention completion criteria, defined as completion of at least four $(80 \%)$ intervention sessions. Missing data was not imputed. Consistent with SCED best-practice [32], daily assessment data was analysed using visual analysis and within-case statistical analysis. Visual analysis was performed using the SCED Package for $\mathrm{R}$ [33]. This uses ordinary least squares regression to create trend lines and Median Absolute Deviation to provide a standardized visualization of data spread, which are considered an advancement on other visual analysis strategies [34, 35]. Aligned with the idiographic nature of SCED research, we refer to participants using pseudonyms throughout our results.

Tau-U tests determined statistical significance of data overlap between variance envelopes and independence of trend lines between the baseline phase (session 1 though to session 2), the active intervention phase (Session 2 through to one week after Session 4), and follow-up (up until to session 5), whilst controlling for baseline trend [26]. Due to the small sample, weekly assessment data was analysed using descriptive methods only.

Participant interview data was analysed thematically [36]. Focus group data was analysed using a framework approach to allow for a structured approach to address study aims [37].

\section{Results}

Recruitment took longer than anticipated and after nine months only 10 participants had consented. Only $15.2 \%$ of hospice referrals met eligibility criteria, and just $19.2 \%$ of those consented (Fig. 1).

The five participants (50\%) who completed the intervention provided a sufficient sample size for SCED analysis, in which successful delivery to three participants is

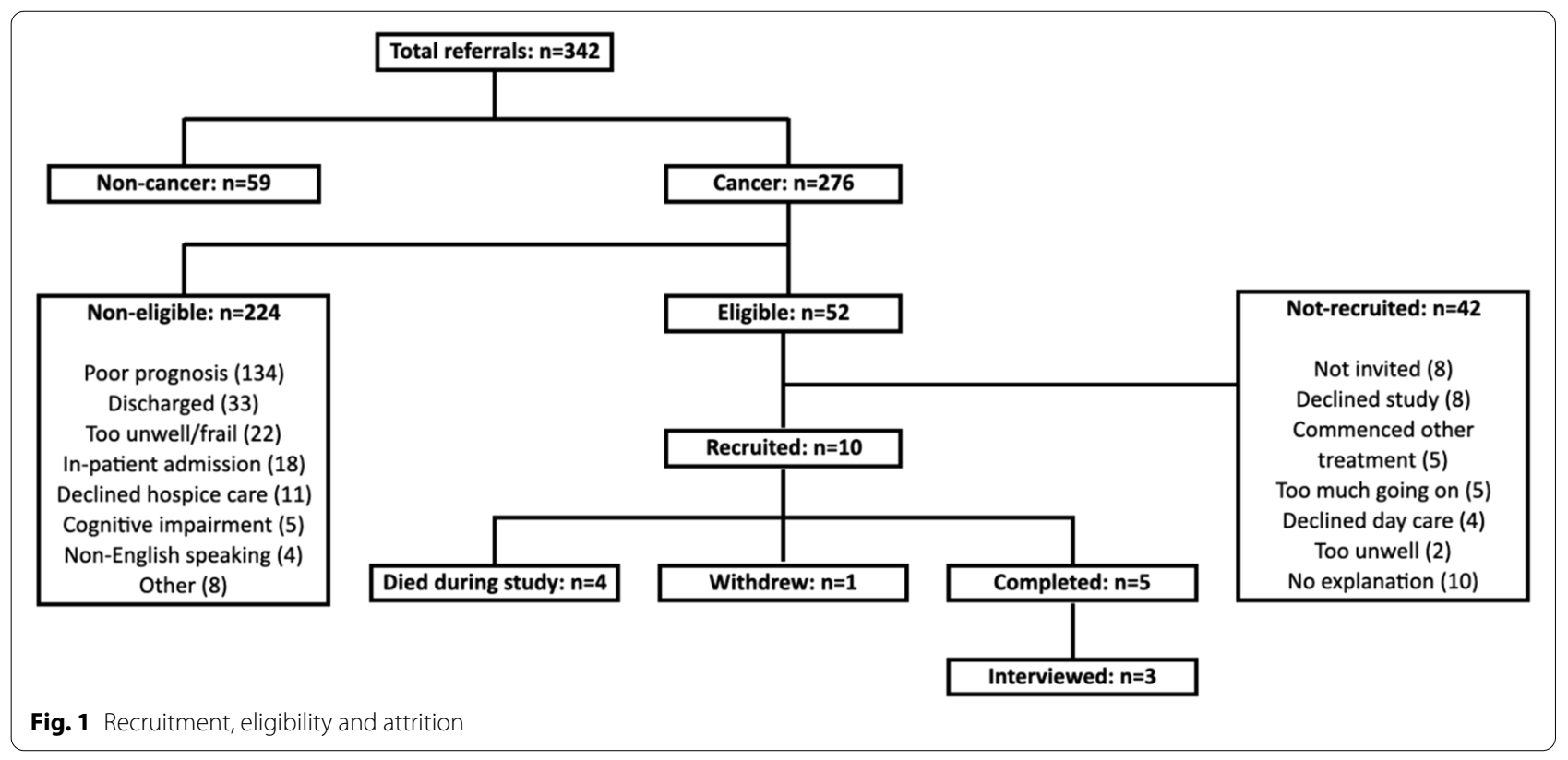


considered a minimum to demonstrate reliability of effect [38]. Outcome measure completion was high: no participants missed data on weekly measures, half completed 97\% or more daily assessment points (two non-completers failed to engage with daily assessments entirely). Only one participant opted for smart-phone based daily data collection.

Of the participants who did not complete the intervention, one withdrew, and four died part-way through (Table 2).

Compared to previous literature, our sample reported poorer baseline quality of life [28]. Intervention completers were slightly below threshold for clinically-significant distress $(<4)$ at baseline [39]. Physical and functional quality of life were lower in non-completers indicating poorer baseline health status (Table 3).

\section{Intervention effectiveness}

Visual analysis highlights problematic ceiling and floor effects in daily BAM and single-item QoL assessments (Fig. 2). Additionally, baseline periods lacked ideal levels of stability, and there was little distinction between experimental phases (baseline to intervention and intervention to follow-up). Weekly assessments offered more assessment sensitivity and variability over time.

Elizabeth, Andrew, and Graham all showed deteriorating quality of life during baseline; for both Elizabeth and Andrew this then stabilized and improved during the intervention. Tau- $\mathrm{U}$ analysis (Table 4) confirmed this improvement was significant in only one case (Elizabeth). The lack of further significant change from intervention to follow-up indicates that gains were maintained. James and Michelle reported non-significant decreasing quality of life through the intervention.

Elizabeth's data demonstrates a ceiling effect on the BAM. Both James and Graham reported decreasing psychological flexibility, and in James's case this was significant throughout. Andrew reported a nonsignificant increase in psychological flexibility from baseline to intervention, and Michelle demonstrated significant improvement in psychological flexibility occurring between intervention and follow-up.

Weekly assessment change scores (Fig. 3) demonstrate stability in distress for four participants, and improvement for the fifth; for some (e.g. Elizabeth) there was a measurement ceiling-effect which prevented improvement being recorded. Four showed improvement in at least some quality of life sub-domains, however two participants (Graham, Michelle) demonstrate a considerable decrease through follow-up. For Michelle, more so than Graham, it is encouraging that distress and psychosocial quality of life stayed stable, even though physical health deteriorated.
Two participants (James, Andrew) demonstrated a clear mapping of improvement of sub-components of psychological flexibility (openness, awareness, engagement) following delivery of those specific modules, and this is consistent with the pattern of outcome improvements too.

The sample is too small for confident conclusions to be drawn, but there is some evidence that increased psychological flexibility maps closely onto buffering distress increases and maintaining psychosocial quality of life, even where physical and functional quality of life deteriorated.

\section{Qualitative feedback}

Three intervention completers took part in interviews, and fifteen staff took part in focus groups. These qualitative data are described in three themes: intervention effectiveness, intervention acceptability, and suggestions for future research.

\section{Perceived intervention effectiveness}

All participants reported benefits from taking part, including facing the reality of end of life:

“...I wasn't sure whether I would die with dignity... he helped me through that." (James)

And being able to discuss fears and emotions honestly:

"...you can sit and talk and you're not holding anything back...somebody different to your family..." (Graham)

Participants describe using the coping skills taught outside of the intervention sessions:

"...it was the meditation part of it. Yeah. Mhhm because I used to do that quite a lot... And it was yeah, it was really good... the other night I used it to get to sleep." (Elizabeth).

The intervention helped participants to accept their current circumstances:

"I always had this mental picture of lying on my death bed surrounded by my family and I realised that that wasn't going to happen, you know. And he worked me through my feelings with that one." (James).

Staff involved in focus groups reported positive perceptions too, based on their conversations with participants:

"...he only made it to two sessions, two or three, and he had a great benefit... his wife noticed a difference as well...she felt that he was definitely... lighter when he came back from session." (FG2) 
Table 2 Participant (pseudonym) characteristics and intervention engagement

\begin{tabular}{|c|c|c|}
\hline Participant & Clinical description & Engagement / session order \\
\hline \multicolumn{3}{|c|}{ Intervention completers } \\
\hline Elizabeth & $\begin{array}{l}58 \text { year old single woman, with breast cancer. Elizabeth moved in } \\
\text { with her sister during treatment, fearful of loss of independence } \\
\text { and mobility. Her distress levels were low when she entered the } \\
\text { intervention. At the time of referral she was undergoing palliative } \\
\text { chemotherapy. She accessed orthopaedic services to discuss } \\
\text { surgical options for her symptoms. Clinical data indicated that } \\
\text { after a good chemotherapy response, Elizabeth was discharged } \\
\text { from hospice community services } 10 \text { months after referral }\end{array}$ & $\begin{array}{l}\text { Session 1: Module A } \\
\text { Session 2: Module B \& C } \\
\text { Session 3: Module D } \\
\text { (3 week gap) } \\
\text { Session 4: Module E } \\
\text { Session 5: Module F } \\
\text { Interview: } 7 \text { weeks later }\end{array}$ \\
\hline James & $\begin{array}{l}81 \text { year old widower, with oesophageal cancer. James had grown } \\
\text { children living locally, with grandchildren. He was receiving pal- } \\
\text { liative radiotherapy. James was moderately distressed, reviewing } \\
\text { life meaning. He continued to have active engagement with a } \\
\text { variety of hospice support services }\end{array}$ & $\begin{array}{l}\text { Session 1: Module A } \\
\text { Session 2: Module B \& D } \\
\text { Session 3: Module E } \\
\text { Session 4: Module C } \\
\text { Session 5: Module F } \\
\text { Interview } 13 \text { weeks later }\end{array}$ \\
\hline Graham & $\begin{array}{l}66 \text { year old with oesophageal cancer and chronic obstructive pul- } \\
\text { monary disorder. Graham was living with a supportive partner, } \\
\text { and had children in other parts of the UK. He was not especially } \\
\text { distressed but low in mood at times. Graham continued to } \\
\text { access hospice day services }\end{array}$ & $\begin{array}{l}\text { Session 1: Module A } \\
\text { Session 2: Module B \& C } \\
\text { Session 3: Module D } \\
\text { Session 4: Module E } \\
\text { Session 5: Module F } \\
\text { Interview } 2 \text { weeks later }\end{array}$ \\
\hline Andrew & $\begin{array}{l}73 \text { year old man with prostate cancer. He had a supportive wife } \\
\text { and grown children. Andrew stopped conventional treatment } \\
\text { when he was referred to hospice care. Overwhelmed by his } \\
\text { diagnosis, and distressed, he accessed mainly emotional and } \\
\text { psychological support. Other services used included occupa- } \\
\text { tional therapy }\end{array}$ & $\begin{array}{l}\text { Session 1: Module A } \\
\text { Session 2: Module B \& E } \\
\text { Session 3: Module D } \\
\text { Session 4: Module C } \\
\text { Withdrew } 3 \text { weeks later }\end{array}$ \\
\hline Michelle & $\begin{array}{l}46 \text { year old woman with cervical cancer. She had a long history of } \\
\text { interpersonal difficulties, relatively chaotic lifestyle, and previous } \\
\text { episodes of psychological problems which were now stable. } \\
\text { Michelle had completed palliative chemotherapy and sought } \\
\text { emotional and benefits advice. She appeared avoidant of think- } \\
\text { ing of her illness }\end{array}$ & $\begin{array}{l}\text { Session 1: Module A } \\
\text { Session 2: Module B \& } \\
\text { Session 3: Module D } \\
\text { Session 4: Module E } \\
\text { Session 5: Module F } \\
\text { (Over an extended } 13 \text { week period) }\end{array}$ \\
\hline \multicolumn{3}{|c|}{ Withdrawn or deceased participants } \\
\hline Sally & $\begin{array}{l}48 \text { year old woman with lung cancer. Sally had children and young } \\
\text { grandchildren, and was supported by her husband. At the time } \\
\text { of entering the intervention, she was moderately distressed. Sally } \\
\text { was receiving only palliative treatment and died } 4 \text { months after } \\
\text { referral to the hospice. She had received visits from the hospice } \\
\text { nursing service, but did not access any other hospice support or } \\
\text { care services }\end{array}$ & $\begin{array}{l}\text { Session 1: Module A } \\
\text { Session 2: Module B \& C } \\
\text { Formally withdrew from study } 11 \text { weeks after this, and died two } \\
\text { weeks later }\end{array}$ \\
\hline Mary & $\begin{array}{l}73 \text { year old woman, with pancreatic cancer. She had a long history } \\
\text { of psychological difficulties, although her mental health was cur- } \\
\text { rently stable. Mary was living alone, supported by her daughter. } \\
\text { She appeared resilient throughout her time in the study. She was } \\
\text { being cared for with ongoing pain and symptom management } \\
\text { and in addition to hospice nurse visits, she accessed benefit } \\
\text { support and diabetic nurse care. Mary died almost three months } \\
\text { after her referral into hospice services }\end{array}$ & $\begin{array}{l}\text { Session 1: Module A } \\
\text { Session 2: Module B \& C } \\
\text { Withdrew from study the following week, and died five weeks later }\end{array}$ \\
\hline John & $\begin{array}{l}71 \text { year old man with bladder cancer, who was undergoing pallia- } \\
\text { tive chemotherapy. He had increasing levels of pain and nausea } \\
\text { and became socially withdrawn when told his cancer wasn't } \\
\text { curable. After two sessions he withdrew from the study because } \\
\text { he decided to return to work. John was admitted to hospital five } \\
\text { months after referral into hospice community services. He died } \\
\text { in hospital a few weeks later }\end{array}$ & $\begin{array}{l}\text { Session 1: Module A } \\
\text { Session 2: Module B \& C } \\
\text { Withdrew from study five weeks later }\end{array}$ \\
\hline Daniel & $\begin{array}{l}69 \text { year old man, with cancer of the digestive organs and perito- } \\
\text { neum. Daniel was married, with grown children, and was well } \\
\text { supported by his wife. Daniel became increasingly unwell over } \\
\text { a short period time following hospitalisation for a suspected } \\
\text { infection. He was receiving palliative treatment for pain, fatigue } \\
\text { and agitation. Daniel died at home seven weeks after referral to } \\
\text { hospice community services }\end{array}$ & $\begin{array}{l}\text { Session 1: Module A } \\
\text { Withdrew from the study before Session } 2\end{array}$ \\
\hline
\end{tabular}


Table 2 (continued)

\begin{tabular}{|c|c|c|}
\hline Participant & Clinical description & Engagement / session order \\
\hline Michael & $\begin{array}{l}72 \text { year old man, diagnosed with colon cancer and liver metas- } \\
\text { tases. Michael was living with his wife, and with children and } \\
\text { grandchildren. Michael was relatively accepting, with low levels } \\
\text { of distress throughout the intervention. He was being treated } \\
\text { primarily for pain and accessed physiotherapy services through } \\
\text { the hospices. Michael was admitted to inpatient care at the } \\
\text { hospice following a hospital stay. He died in the hospice three } \\
\text { months after his first referral }\end{array}$ & $\begin{array}{l}\text { Sessions 1, } 2 \text { and } 3 \text { covered only Module A, and took place over a } \\
\text { longer-than-specified period of time ( } 7 \text { weeks): patient died two } \\
\text { weeks later }\end{array}$ \\
\hline
\end{tabular}

Table 3 Descriptive data for outcome and psychological flexibility at baseline (full sample)

\begin{tabular}{|c|c|c|c|c|c|c|c|}
\hline & \multirow[b]{2}{*}{$\begin{array}{l}\text { Possible score } \\
\text { range }\end{array}$} & \multicolumn{2}{|c|}{ Full sample } & \multicolumn{2}{|c|}{$\begin{array}{l}\text { Intervention completers } \\
(n=5)\end{array}$} & \multicolumn{2}{|c|}{ Non-completers $(n=4)^{d}$} \\
\hline & & Mean & $\begin{array}{l}\text { Standard } \\
\text { deviation }\end{array}$ & Mean & $\begin{array}{l}\text { Standard } \\
\text { deviation }\end{array}$ & Mean & $\begin{array}{l}\text { Standard } \\
\text { deviation }\end{array}$ \\
\hline \multicolumn{8}{|l|}{ Quality of life ${ }^{\mathrm{a}}$} \\
\hline Physical & $0-28$ & 13.48 & 6.32 & 15.2 & 7.36 & 11.75 & 5.06 \\
\hline Social & $0-28$ & 20.44 & 5.19 & 19.68 & 5.57 & 21.2 & 5.37 \\
\hline Emotional & $0-24$ & 15.35 & 6.47 & 13.2 & 7.01 & 17.5 & 5.68 \\
\hline Functional & $0-28$ & 11.91 & 5.86 & 13.06 & 7.71 & 10.75 & 2.87 \\
\hline Palliative specific & $0-76$ & 59.58 & 19.70 & 59.9 & 16.46 & 59.25 & 25.95 \\
\hline Distress $^{b}$ & $0-10$ & 4.42 & 2.40 & 3.6 & 3.05 & 5.25 & 0.96 \\
\hline Psychological Flexibility ${ }^{c}$ & $0-126$ & 83.83 & 26.42 & 84.4 & 35.64 & 83.25 & 12.91 \\
\hline
\end{tabular}

${ }^{a}$ FACIT-PAL sub-scales (higher scores indicate better quality of life)

${ }^{\mathrm{b}}$ Higher score indicates more distress

' Higher score indicates more psychological flexibility

${ }^{\mathrm{d}}$ No data available for one participant (Daniel)

\section{Intervention acceptability}

Patients found the intervention acceptable, with participants responding positively about intervention content. Intervention length was thought appropriate by all but one participant (who expressed a preference for a shorter intervention); they warned that expecting more would have been difficult due to the challenge of deteriorating health:

\section{"I found them just the right...I don't think I could have went any longer." (Graham)}

There was some variation in opinions around preferred metaphors:

"...it's just not the way that I think...other people it might be, but not me." (Elizabeth)

And some participants suggested that the intervention might benefit more people if the language was simplified.

"I don't know whether I was rationalising it, I don't know, but I put my difficulty down to age. Compre- hension, you know, trying to comprehend...I think a lot of people would get benefit if it was just tempered down a wee bit." (James).

Patients were supportive of delivering the intervention in the hospice setting:

"...certainly much more convenient, it's a conducive environment as well...it's nice that you can come to this protected environment..." (James)

And their views on offering the intervention at this specific transition point into palliative care were also positive:

"I would say it would be the best time. Cause people can get into a mindset if you leave it too long and they'll never get out of it. So if you get them at the beginning...get there quick." (Elizabeth)

Reference here to 'the beginning' might also support a move to earlier recruitment in the care pathway, given that the boundary between curative and palliative care is also moving earlier. 
Elizabeth
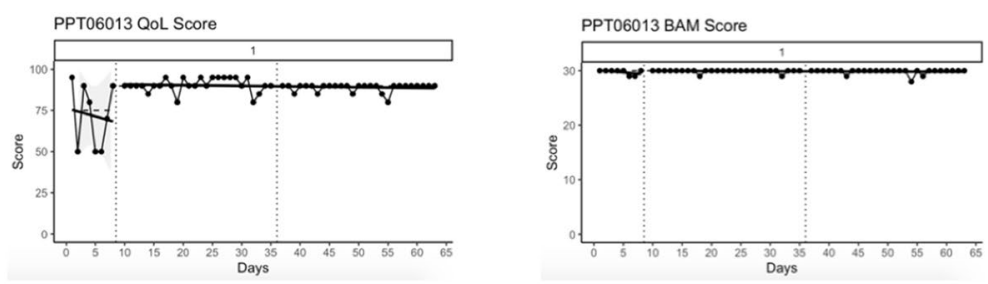

James
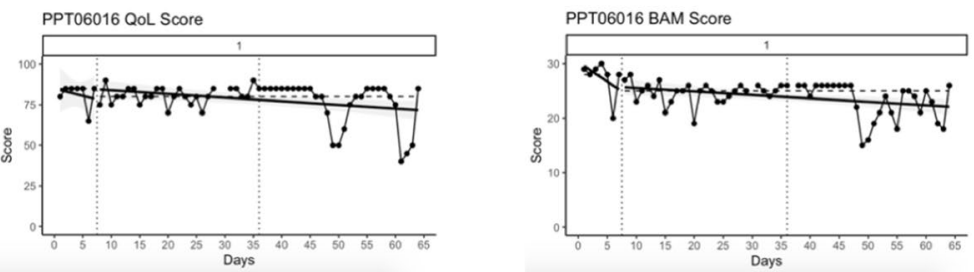

Graham
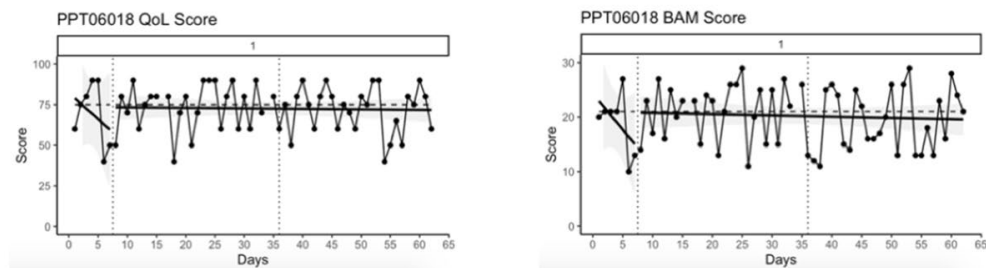

Andrew (note: did not complete assessments after Session 4)
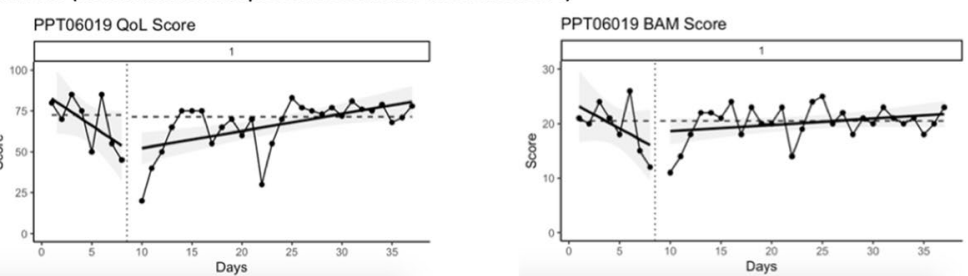

Michelle
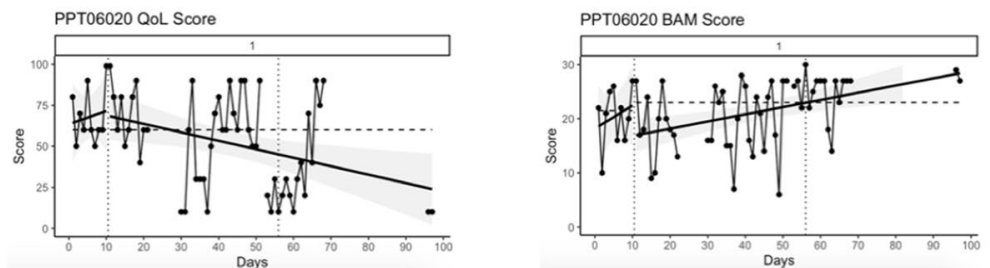

Fig. 2 Graphical summary of daily assessed, single-item quality of life question (left) and psychological flexibility assessed using the BAM (right). Ordinary least square regression trend lines are displayed with the solid straight line; Median Absolute Deviation variance is indicated by the shaded area behind the data plots); dotted vertical lines indicate end of baseline phase and end of intervention phase

Staff focus groups added further depth to understanding acceptability issues. Staff reported that some participants struggled with practical components, having expected more traditional 'talk' therapy. One participant told staff that time between sessions was essential to think through answers and reflections on exercises:

"...he's [the patient] extremely intelligent...these questions that were asked made him have to do homework and have to think more, and he found them extremely challenging." (FG3).

Staff talked frequently about the prevalence of distress and the need for psychological interventions, highlighting a perceived expectation (from patients) that this will be supported by hospice nurses.

“...sometimes you go and patients are quite anxious...you're non-threatening...there's a bit more of 
Table 4 Tau-U statistical analysis of changes in daily assessed quality of life (single-item) and psychological flexibility (BAM)

\begin{tabular}{|c|c|c|c|c|}
\hline & \multicolumn{2}{|l|}{ Quality of Life } & \multicolumn{2}{|l|}{ Psychological flexibility } \\
\hline & Baseline to intervention & Intervention to follow-up & Baseline to intervention & $\begin{array}{l}\text { Intervention } \\
\text { to follow-up }\end{array}$ \\
\hline Elizabeth & $\begin{array}{l}\text { Tau- } U=0.62 \\
p=.01^{*}\end{array}$ & $\begin{array}{l}\text { Tau-U }=-0.26 \\
p=.11\end{array}$ & $\begin{array}{l}\text { Tau- } U=.23 \\
p=.35\end{array}$ & $\begin{array}{l}\text { Tau- } U=-.09 \\
p=.60\end{array}$ \\
\hline James & $\begin{array}{l}\text { Tau }-U=-0.11 \\
p=.64\end{array}$ & $\begin{array}{l}\text { Tau- } U=-.31 \\
p=.06\end{array}$ & $\begin{array}{l}\text { Tau }-U=-0.71 \\
P<.01^{* *}\end{array}$ & $\begin{array}{l}\text { Tau- } U=-.43 \\
p=<.01^{* *}\end{array}$ \\
\hline Graham & $\begin{array}{l}\text { Tau }-\mathrm{U}=-.05 \\
p=.86\end{array}$ & $\begin{array}{l}\text { Tau- } U=-.05 \\
p=.076\end{array}$ & $\begin{array}{l}\text { Tau }-U=.10 \\
p=.70\end{array}$ & $\begin{array}{l}\text { Tau }-U=-.064 \\
p=.69\end{array}$ \\
\hline Andrew & $\begin{array}{l}\text { Tau-U }=.29 \\
p=.16\end{array}$ & Missing data & $\begin{array}{l}\text { Tau-U }=.29 \\
p=.16\end{array}$ & Missing data \\
\hline Michelle & $\begin{array}{l}\text { Tau- } U=-.32 \\
p=.09\end{array}$ & $\begin{array}{l}\text { Tau- } U=-.35 \\
p=.06\end{array}$ & $\begin{array}{l}\text { Tau-U }=-.308 \\
p=.69\end{array}$ & $\begin{array}{l}\text { Tau-U }=.56 \\
p<.01^{*}\end{array}$ \\
\hline
\end{tabular}

* indicates a statistically significant change between intervention phase in the desired direction

** indicates a statistically significant change contrary to expected direction of effect

an intimacy there because you're in their house... you've build that little bit of rapport..." (FG3).

However, some staff thought that public perceptions of hospices as only having relevance for end of life might be problematic:

"the people who are most likely to turn down coming to the hospice ...[are] the people who would actually benefit the most..." (FG2).

\section{Future research using the BEACHeS intervention}

Participants were asked to reflect on how the BEACHeS intervention might evolve in the future, and there was a range of views expressed. Support for re-working this intervention for group delivery was not strong: participants felt this would have prevented in-depth discussion, and willingness to openly discuss the difficult emotions that accompany a terminal diagnosis. One participant described being 'open' to the idea and could see a potential benefit, but for another it would have been a strong deterrent.

“...culturally, we're not ready for this dynamic type of group work. People are guarded...you know, my illness is personal to me...No, I think the one-to-one is much more therapeutic..." (James)

Views on the inclusion of caregivers in the intervention were varied, but there was not a strong appetite for their inclusion:

"It's just my partner, I dinnae ken if she'd want to come in or no eh. She's funny that way isn't she?" (Graham)
There were mixed views from patients on whether the intervention should be nurse-led, with some feeling that psychologists were the experts:

"I think leave the palliative care staff to do the palliative care; let's do the drug regime and let's make you comfortable at night and let's get you food, and leave that side of it, but leave the grey-matter stuff to the psychologists." (James)

Importantly, staff felt that recruiting at hospice referral did not adequately capture patients at the point of psychological transition, but that this occurred earlier in the cancer trajectory:

\section{"...often the patients that we've got have already gone} through that stage." (FG2)

The proposed solution was to recruit from the hospital setting:

"the erm hospital CNS's you know working with oncology and seeing cause they see them at a much earlier stage, they might be the people that help a bit earlier." (FG2)

Sufficiently trained, these staff expressed interest in delivering this new intervention:

"...I think it would fit in with what we do if we had that proper training..." (FG2).

\section{Discussion}

We aimed to develop a manualised ACT-based coaching intervention for people with non-curative cancer transitioning into palliative care. We explored acceptability and initial effectiveness for improving quality of life and distress. 

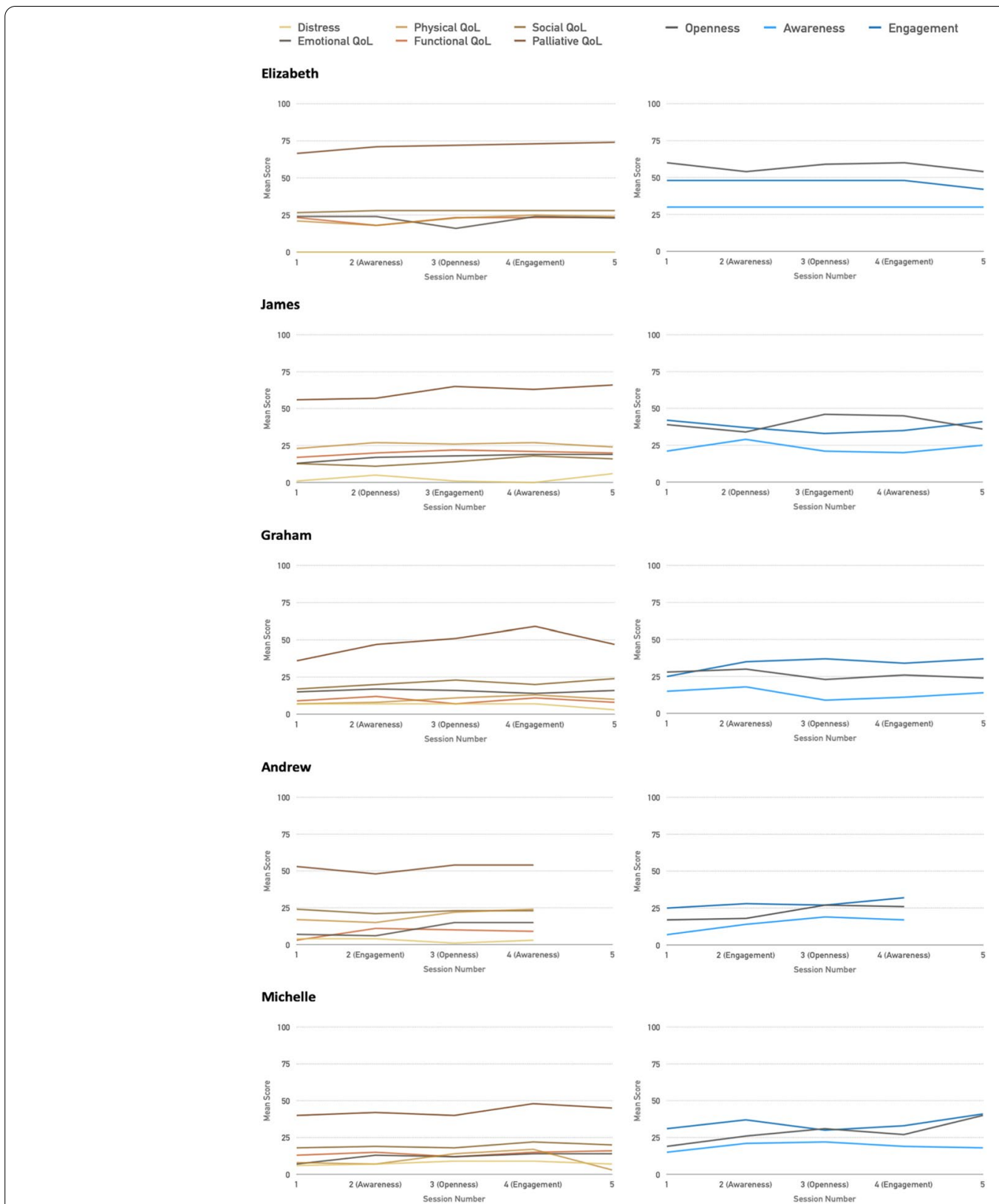

Fig. 3 Graphical summary of weekly assessed outcomes (left) and sub-components of psychological flexibility (right) with module topic specified per participant

With relatively minor modifications, we were able to use existing ACT metaphors and exercises to ensure suitability for palliative care populations. Participants' qualitative data indicated intervention acceptability, and our $50 \%$ completion rate is in line with other research [15]. Participants reported that they learned useful emotion management techniques and appreciated the space to talk about worries and fears. Some individual preferences against specific metaphors and exercises emphasises the need for alternative content options, though the broad use of metaphor was acceptable.

Though designed for weekly delivery, this was not practicable; in the context of rapid and unpredictable health status changes, flexibility is essential. For some, this may mean a less rigid delivery schedule over a greater number of weeks; for others a more intensive delivery over a shorter period of time. Flexibility around setting may also be beneficial to reduce burden 
of travel or resistance to visiting the hospice setting. Given the growth of telehealth over the past year, it may also be useful to consider virtual delivery via telephone or video conferencing.

Our sample had poorer baseline quality of life than comparative samples [28]. Still, weekly assessments demonstrated preliminary evidence for a positive effect on this outcome. Distress remained stable for most: as a tentative hypothesis, we believe our intervention may have buffered against the increased distress often associated with physical health deterioration [5]. Our expected increase in psychological flexibility was not demonstrated, but this may be because of inadequate follow-up duration.

Daily assessment data failed to robustly demonstrate the statistically significant Tau-U effects that we would hope from SCED studies. We believe this may, in part at least, be due to measurement floor and ceiling effects. The complexity of palliative care[40] might mean that daily assessments are over-sensitive and traditional approaches of recording outcomes as a calculated 'average' over a set-period of time might be more psychometrically informative.

\section{Strengths and limitations}

Our intervention was designed to have long-term costeffectiveness through brevity and manualisation, comparing favourably against other ACT trials in palliative care $[13,16]$. Rather than progressing straight to a feasibility trial, we developed the intervention in an empirical and evidence-based way using integrated mixed-methods. Doing this using an established and real-world delivery (SCED) method enabled us to demonstrate safety, acceptability and tentative efficacy. We ensured optimal likelihood of success by assessing the competency of facilitators, and rates of attrition and missing data were all positively indicated.

There are limitations. First, we did not include outcome assessment after the follow-up session. Second, we were unable to recruit partial-completers to the qualitative interview; most died prior to invitation. In future trials, this feedback would be beneficial. Third, as outlined above, we had some issues with our measures. Finally, there was a bias towards recruitment of an already accepting, low-distress sample.

\section{Implications}

SCEDs do not require a control group, but without this it is premature to conclude that outcome improvements are a direct result of our intervention. These data, however, certainly support further testing using designs incorporating randomisation and blinding. Such work should aim to investigate the distress-buffering hypothesis generated from our interpretation of weekly assessments.

Our work highlights important methodological considerations for future psychological intervention research in palliative settings. Given that our recruitment rates were lower than anticipated, future trials may wish to extend recruitment beyond only people with cancer for added generalizability and potential population capture. Despite staff buy-in, 42 otherwise eligible patients were not invited to participate; clinical gatekeeping is an oftenreported research barrier [41] which must be overcome.

Our four-month life-expectancy eligibility criteria (a) excluded many hospice referrals, and (b) did not effectively reduce attrition. Recruitment earlier in the treatment pathway is, therefore, recommended, for example by shifting the point of study recruitment to the hospital setting at the point of diagnosis of incurable disease, rather than after a hospice-care referral has been made. Provision at this earlier time point would enable participants to make better and longer use of the skills learnt, particularly before the more unpredictable end of life phase begins, and may offer broader benefit to those who may be reluctant to otherwise engage with hospice services.

For those with stable illness, intervention completion rates were high. However, trial length was problematic for those with deteriorating health. Alternative, compressed, delivery is worthy of investigation, though this raises challenges related to homework and skill practice. Furthermore, those who completed the intervention were typically lower in distress at baseline; future work should recruit a sample with higher distress at baseline in whom higher efficacy might be hypothesised.

Regarding delivery and content, two final points are noteworty. First, whilst our intervention is reasonably pitched for adults, changes to presentation and content might be needed for younger populations. Second, our use of highly-trained psychological therapists is infeasible for long-term implementation: future research should explore whether fidelity and efficacy are maintained in delivery by other members of the healthcare team.

\section{Conclusion}

Our data adds to the growing evidence base supporting the use of ACT for people with advanced cancer. We successfully developed an acceptable intervention, and demonstrated some level of initial effectiveness. We have demonstrated the utility (and challenges) of using SCEDs in this setting, notwithstanding some measurement issues. We are planning a feasibility trial of this intervention with an adapted design to improve recruitment and attrition rates. 


\section{Acknowledgements}

We would like thank our participants for giving their time and energy to contribute to this research. We would also like to acknowledge the input of our clinical collaborators, and members of our Patient and Stakeholder Reference Group (Laura Chapman, Kate Nolan, Laurel Morgan-Hughes, Susan Lawson \& Esme Radin). We are grateful to Lee Hulbert-Williams for undertaking the independent competency testing of our intervention facilitators, and to Alison Farmer, Jennifer Gregg, Pandora Patterson, Ray Owen, and Richella Ryan for volunteering their time to independently peer-review the intervention manual.

\section{Author's contributions}

$\mathrm{NHW}, \mathrm{BS}$ and DG originated the idea for the study. NHW and BS led the funding application, with input from DG, AF, JSp, JSt and SM. NHW, BS, AF and SN led applications for ethical and research governance approval. DG and NHW wrote the initial intervention manual, with input from SN and final approval of all co-authors. All co-authors were involved in various aspects of recruitment, data collection/analysis and oversight of the study. DG and JK were the intervention facilitators for the trial. SN and NHW undertook analysis of the SCED data. BS, SN and AF analysed the qualitative data. NHW and BS drafted the manuscript. All authors read and approved the final manuscript.

\section{Funding}

This work was funded by a research grant from Macmillan Cancer Support (Grant \# 6488043).

\section{Availability of data and materials}

The datasets generated and/or analysed during the current study are not publicly available in accordance with our informed consent agreement with participants, but are available from the corresponding author on reasonable request in a de-identified format.

\section{Declarations}

\section{Ethical approval and consent to participate}

All study protocols received ethical and research governance approvals from the UK Health Research Authority (Ref: 18/WA/0087). Study methods were carried out in accordance with principles for medical research involving human subjects as laid down in the World Medical Association Declaration of Helsinki. Informed consent to participate was obtained from all participants.

\section{Consent for publication}

All participants provided consent for their data to be used in publication of the study findings, including the allocation of a pseudonym for anonymity.

\section{Competing interests}

The authors declare that they have no competing interests.

\section{Author details}

${ }^{1}$ Centre for Contextual Behavioural Science, School of Psychology, University of Chester, Chester, UK. ${ }^{2}$ School of Health in Social Science, The University of Edinburgh, Edinburgh, UK. ${ }^{3}$ Marie Curie Hospice, Edinburgh, UK. ${ }^{4}$ Chester, UK.

Received: 25 November 2020 Accepted: 11 June 2021

Published online: 25 June 2021

\section{References}

1. The Global Cancer Observatory. All cancers (World Health Organisation Report). Accessed 20 Oct 2020 from https://gco.iarc.fr/today/data/facts heets/cancers/39-All-cancers-fact-sheet.pdf.

2. Maddams J, Utley M, Møller H. Projections of cancer prevalence in the United Kingdom, 2010-2040. Br J Cancer. 2012;107(7):1195-202. https:// doi.org/10.1038/bjc.2012.366.

3. Bone AE, Gomes B, Etkind S, et al. What is the impact of population ageing on the future provision of end-of-life care? Population-based projections of place of death. Palliat Med. 2017;32(2):329-36. https://doi.org/10. 1177/0269216317734435.
4. National Institute for Health and Clinical Excellence. Quality standard for end of life care for adults. Accessed 20 Oct 2020 from https://www.nice. org.uk/guidance/qs13/documents/qs13-end-of-life-care-for-adults-quali ty-standard-large-print-version2.

5. Murray SA, Kendall M, Grant E, et al. Patterns of social, psychological, and spiritual decline toward the end of life in lung cancer and heart failure. J Pain Symptom Manage. 2007;34(4):393-402. https://doi.org/10.1016/j. jpainsymman.2006.12.009.

6. Gao W, Bennett MI, Stark D, et al. Psychological distress in cancer from survivorship to end of life care: prevalence, associated factors and clinical implications. Eur J Cancer. 2010;46(11):2036-44. https://doi.org/10.1016/j. ejca.2010.03.033.

7. Larkin PJ, De Casterlé BD, Schotsmans P. Towards a conceptual evaluation of transience in relation to palliative care. J Adv Nurs. 2007;59(1):86-96. https://doi.org/10.1111/j.1365-2648.2007.04311.x.

8. Lund S, Richardson A, May C. Barriers to advance care planning at the end of life: an explanatory systematic review of implementation studies. PLoS ONE. 2015;10(2): e0116629. https://doi.org/10.1371/journal.pone.01166 29.

9. Hayes SC, Luoma JB, Bond FW, et al. Acceptance and commitment therapy: model, processes and outcomes. Behav Res Ther. 2006;44(1):125. https://doi.org/10.1016/j.brat.2005.06.006.

10. Hulbert-Williams NJ, Owen R, Nelson C. Acceptance and commitment therapy (ACT) for cancer patients. In: Breitbart W, Butow PN, Jacobsen PB et al. Psycho-oncology (4th edn.). New York: Oxford University Press 2021.

11. Hulbert-Williams N, Beatty L, Dhillon H. Psychological support for patients with cancer: evidence review and suggestions for future directions. Curr Opin Support Palliative Care. 2018;12(3):276-92. https://doi.org/10.1097/ SPC.0000000000000360.

12. Arch J, Fishbein JN, Ferris MC, et al. Acceptability, feasibility, and efficacy potential of a multimodal acceptance and commitment therapy intervention to address psychosocial and advance care planning needs among anxious and depressed adults with metastatic cancer. J Palliat Med. 2020;23(10):1380-5. https://doi.org/10.1089/jpm.2019.0398.

13. Rost AD, Wilson K, Buchanan $E$, et al. Improving psychological adjustment among late-stage ovarian cancer patients: examining the role of avoidance in treatment. Cogn Behav Pract. 2012;9(4):508-17. https://doi.org/ 10.1016/j.cbpra.2012.01.003.

14. Mosher CE, Secinti E, Li R, et al. Acceptance and commitment therapy for symptom interference in metastatic breast cancer patients: a pilot randomized trial. Support Care Cancer. 2018;26(6):1993-2004. https://doi. org/10.1007/s00520-018-4045-0.

15. Wells-Di Gregorio SM, Marks DR, DeCola J, et al. Pilot randomized controlled trial of a symptom cluster intervention in advanced cancer. PsychoOncology. 2018;28(1):76-84. https://doi.org/10.1002/pon.4912.

16. Serfaty $M$, Armstrong $M$, Vickerstaff $V$, et al. Acceptance and commitment therapy for adults with advanced cancer (CanACT): a feasibility randomised controlled trial. PsychoOncology. 2019;28:488-96. https:// doi.org/10.1002/pon.4960.

17. Hulbert-Williams NJ, Norwood S, Gillanders D, et al. Brief Engagement and Acceptance Coaching for Community and Hospice Settings (the BEACHeS Study): protocol for the development and pilot testing of an evidence-based psychological intervention to enhance wellbeing and aid transition into palliative care. Pilot Feasibility Stud. 2019;5:104. https:// doi.org/10.1186/s40814-019-0488-4

18. Curry L, Nembhard I, Bradley E. Qualitative and mixed methods provide unique contributions to outcomes research. Circulation. 2009;119(10):1442-52. https://doi.org/10.1161/CIRCULATIONAHA.107. 742775.

19. Rayment J, Lanlehin R, McCourt C, et al. Involving seldom-heard groups in a PPI process to inform the design of a proposed trial on the use of probiotics to prevent preterm birth: a case study. Res Involv Engage. 2017;3(1):11. https://doi.org/10.1186/s40900-017-0061-3.

20. Heyvaert M, Onghena P. Randomization tests for single-case experiments: state of the art, state of the science, and state of the application. J Contextual Behav Sci. 2014;3:51-64. https://doi.org/10.1016/j.jcbs.2013. 10.002.

21. Holman G, Koerner K. Single case designs in clinical practice: a contemporary CBS perspective on why and how to. J Contextual Behav Sci. 2014;3:138-47. https://doi.org/10.1016/j,jcbs.2014.04.006. 
22. Smith J. Single-case experimental designs: a systematic review of published research and current standards. Psychol Methods. 2012;17(4):51050. https://doi.org/10.1037/a0029312.

23. Quesnel C, Savard J, Simard S, et al. Efficacy of cognitive- behavioral therapy for insomnia in women treated for nonmetastic breast cancer. J Consult Clin Psychol. 2003;71(1):189-200.

24. Preston NJ, Fayers $P$, Walters $S J$, et al. Recommendations for managing missing data, attrition and response shift in palliative and end-of-life care research: part of the MORECare research method guidance on statistical issues. Palliat Med. 2013;27(10):899-907. https://doi.org/10.1177/02692 16313486952.

25. Gast DL, Ledford JR. Single case research methodology: applications in special education and behavioral sciences. 2nd ed. London: Routledge; 2014.

26. Manolov R, Losada JL, Chacón-Moscoso S, et al. Analyzing two-phase single-case data with non-overlap and mean difference indices: Illustration, software tools, and alternatives. Front Psychol. 2016;7:32. https://doi. org/10.3389/fpsyg.2016.00032.

27. Walser RD, Karlin BE, Trockel M, et al. Training in and implementation of acceptance and commitment therapy for depression in the Veterans health administration: therapist and patient outcomes. Behav Res Ther. 2013;51:555-63. https://doi.org/10.1016/j.brat.2013.05.009.

28. LyonsBakitasHegel KDMMT, et al. Reliability and validity of the functiona assessment of chronic illness therapy-palliative care (FACIT-pal) scale. J Pain Symptom Manage. 2019;7(1):23-32. https://doi.org/10.1016/j.jpain symman.2007.12.015.

29. Roth A, Kornblith A, Batel-Copel L, et al. Rapid screening for psychologic distress in men with prostate carcinoma - a pilot study. Cancer. 1998;82(10):1904-8. https://doi.org/10.1002/(SICI)1097-0142(19980515) 82:10\%3c1904:.AID-CNCR13\%3e3.0.CO;2-X.

30. Francis AW, Dawson DL, Golijani-Moghaddam N. The development and validation of the comprehensive assessment of acceptance and commitment therapy processes (CompACT). J Context Behav Sci. 2016;3:134-45. https://doi.org/10.1016/j.jcbs.2016.05.003.

31. Assmann L, Pasi HJ, Gillanders DT et al. The brief acceptance measure: development and initial validation of an ultra-brief measure of psychological flexibility, suitable for daily use. Paper presented at The Chester
Contextual Behavioural Science Research Colloquium, University of Chester, UK, August 28th and 29th 2018.

32. Manolov R, Gast DL, Perdices M, et al. Single-case experimental designs: reflections on conduct and analysis. Neuropsychol Rehabil. 2014;24(34):634-60. https://doi.org/10.1080/09602011.2014.903199.

33. Hussey I. The SCED package for R: simple and robust visualization, analysis, and meta-analysis of A-B single case experimental design data. Accessed 20 Oct 2020 from https://github.com/ianhussey/SCED.

34. Field A. Discovering statistics using IBM SPSS statistics. London: Sage; 2013.

35. Leys C, Ley C, Klein O, et al. Detecting outliers: do not use standard deviation around the mean, use absolute deviation around the median. J Exp Soc Psychol. 2013;49(4):764-6. https://doi.org/10.1016/j.jesp.2013.03.013.

36. Braun V, Clarke V. Using thematic analysis in psychology. Qual Res Psychol. 2016;3(2):77-101.

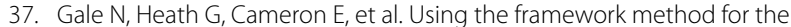
analysis of qualitative data in multi-disciplinary health research. BMC Med Res Methodol. 2013;13(1):117. https://doi.org/10.1186/1471-2288-13-117.

38. Chambless DL, Hollon SD. Defining empirically supported therapies. J Consult Clin Psychol. 1998;66(1):7-18. https://doi.org/10.1615/ihtc15. bma.008489.

39. Mitchell AJ, Hussain N, Grainger L, et al. Identification of patient-reported distress by clinical nurse specialists in routine oncology practice: a multicentre UK study. PsychoOncology. 2011;20:1076-83. https://doi.org/10. 1002/pon.1815.

40. Carduff E, Johnston S, Winstanley C, et al. What does 'complex' mean in palliative care? Triangulating qualitative findings from 3 settings. BMC Palliat Care. 2018;17(1):12. https://doi.org/10.1186/s12904-017-0259-z.

41. Chambers E, Gardiner C, Thompson J, et al. Patient and carer involvement in palliative care research: an integrative qualitative evidence synthesis review. Palliat Med. 2019:33(8):969-84. https://doi.org/10.1177/02692 16319858247.

\section{Publisher's Note}

Springer Nature remains neutral with regard to jurisdictional claims in published maps and institutional affiliations.
Ready to submit your research? Choose BMC and benefit from:

- fast, convenient online submission

- thorough peer review by experienced researchers in your field

- rapid publication on acceptance

- support for research data, including large and complex data types

- gold Open Access which fosters wider collaboration and increased citations

- maximum visibility for your research: over $100 \mathrm{M}$ website views per year

At $\mathrm{BMC}$, research is always in progress.

Learn more biomedcentral.com/submissions 